\title{
Nonparametric Moving Average Control Charts Using Sign and Signed-Rank Statistics
}

\author{
Vilas Yashwant Pawar ${ }^{1}$, Digambar Tukaram Shirke ${ }^{2}$ and Shashikant Kuber Khilare ${ }^{3^{*}}$ \\ ${ }^{1}$ Dep. of Statistics, Dr. Vasantraodada Patil Mahavidyalaya, Tasgaon. (MS) INDIA- 416312. \\ ${ }^{2}$ Dep. of Statistics, Shivaji University, Kolhapur. (MS) INDIA- 416004. \\ ${ }^{3}$ Dep. of Statistics, R. B. Narayanrao Borawake College, Shrirampur. (MS) INDIA- 413709.
}

*Corresponding Author: shashi.khilare@gmail.com

Available online at: www.isroset.org

Accepted 25/Aug/2018, Online 30/Aug/2018

\begin{abstract}
In this paper, we provide two nonparametric moving average control charts based on well-known nonparametric statistics namely sign and signed-rank statistic. These control charts are useful in detecting shifts in the median of the symmetric process distributions. Average run length of these control charts has been studied for various symmetric process distributions. These include the normal, double exponential and Cauchy distributions. Performance of the proposed nonparametric moving average control chart based on the sign statistic is compared with the nonparametric sign chart and the Shewhart X-bar chart. Also, the performance of the proposed nonparametric control chart based on signed-rank statistic is compared with the Shewhart X-bar chart and the 2-of-2 control chart based on the signed-rank statistic. The study reveals that the proposed nonparametric moving average control chart based on sign statistic perform significantly better than the nonparametric sign chart and Shewhart X-bar chart. Also, the performance of the proposed nonparametric moving average control chart based on the signed-rank statistic perform significantly better than the Shewhart X-bar chart and the 2-of-2 chart based on the signed-rank statistics. The gain in the performance is substantial for heavy-tail distributions as compared to lighttail distribution. Robustness study against contamination by outliers for both the proposed charts show satisfactory performance. These chars can be used in practice, since they are simple to use and do not need any distributional assumptions, except symmetry.
\end{abstract}

Keywords- Nonparametric, Sign Statistic, Sign-Rank Statistic, Average Run Length.

\section{INTRODUCTION}

Control charts are useful tools for monitoring/controlling a manufacturing process. Nonparametric control charts are becoming important tools in the field of process control since their application does not require the assumption of any specific probability distribution for the underlying process. Nonparametric control charts are used for detecting the changes in the process median (or mean) or changes in the process variability. The nonparametric control charts are used for monitoring the process median (or mean). These nonparametric control charts are based on the signs computed within samples and used in place of sample means in the Shewhart chart. The chart is labeled to be the nonparametric chart if in-control average run length (ARL) does not depend on the underlying process distribution. In case of charts based on signs, the ARL will be the same for all distributions for which median equal to the target value. In nonparametric control charts, the assumption of normality is not necessary for calculating the control limits. The nonparametric control charts are to be less impacted by outliers. Some of these are based on sign and/or signed-rank statistics by assuming a known incontrol target value for process location.

In the literature review, Abid et al. presented an efficient nonparametric EWMA Wilcoxon signed-rank chart for monitoring location [1]. Amin and Searcy proposed a nonparametric EWMA control chart using the Wilcoxon signed-rank statistic [2]. Amin et al. proposed the control charts based on sign test statistic to monitor the process location and variability [3]. Bakir developed a distributionfree Shewhart control chart for monitoring process center based on the signed-ranks of grouped observations [4]. Bakir proposed the distribution-free quality control charts based on signed-rank-like statistics [5]. Bakir and Reynolds developed a nonparametric cumulative sum control chart 
based on the signed-rank statistic [6]. Chakraborti and Eryilmaz suggested an improved the performance of the signed-rank control chart by applying runs rules [7]. Chakraborti et al. presented an overview of nonparametric control charts for univariate variables data [8]. Coelho et al. proposed the nonparametric signed-rank control charts with variable sampling intervals [9]. Ghute and Shirke developed a nonparametric bivariate signed-rank control chart for process location [10]. Jayathavaj and Pongpullponsak studied the performance of control charts for normal and Weibull data using sign test, MannWhitney test and Hodges-Lehmann estimator [11]. Khilare and Shirke proposed a nonparametric synthetic control chart using sign statistic for monitoring location parameter [12]. Khilare and shirke developed a nonparametric synthetic control chart for process variation using sign statistic based on quartiles [13]. Khilare and Shirke studied the steady-state behavior of nonparametric control charts based on sign statistic to detect shifts in a location [14]. Khoo and Yap developed a moving average control chart for joint monitoring the process mean and variability [15]. Pawar and Shirke developed a nonparametric synthetic control chart for the location using signed-rank statistic [16]. Pawar and Shirke proposed a nonparametric moving average control chart for variability based on sign statistic [17]. Pawar et al. studied the steady-state behavior of the nonparametric synthetic control chart using signed-rank statistic [18]. Pawar et al. developed a nonparametric control chart using sign statistic based on quantiles [19]. Shirke and Barale proposed a nonparametric cumulative sum control chart for process dispersion based on the sign statistic using in-control deciles [20] .

In this paper, we develop nonparametric moving average control charts to monitor the process median of the symmetric distributions. The purpose of the work is to improve the performance of nonparametric control charts for monitoring process median based on sign and/or signed-rank statistics. Khoo and Yap developed a moving average control chart for joint monitoring the process mean and variability [15], which motivated us to undertake the present work.

Rest of the paper is organized as follows: In Section II, the general procedure for the nonparametric moving average control chart is given. In Section III, moving average control charts based on sign and signed-rank statistics have been provided. Section IV, presents the ARL performance of the proposed moving average charts and comparison of the same with other control charts. In Section V, the robustness of the proposed control charts against contamination by outliers is studied. Section VI concludes research work with future directions.

\section{NONPARAMETRIC CONTROL CHART BASED ON MOVING AVERAGES}

Let $\left(\mathrm{x}_{i 1}, \mathrm{x}_{i 2} \ldots, \mathrm{x}_{i n}\right)$ be a sample (subgroup) of size $n(>1)$ of independent observation from the process output at sampling instance $i, i=1,2, \ldots$. The probability distribution of the process is assumed to be continuous and symmetric about the process median $\theta$. We assume that, when the process is in control, $\theta=\theta_{0}$. Let $U_{i}=U\left(x_{i 1}, x_{i 2} \ldots\right.$, $x_{i n}$ ) be a suitable nonparametric statistic for $\theta$ based on the subgroup sample. Our charting statistic is based on the average of the most recent ' $w$ ' $(>1)$ nonparametric statistic defined as

$$
\begin{aligned}
& \psi_{i}=\frac{\left(U_{1}+U_{2}+\ldots+U_{i}\right)}{i} ; \quad i<w \\
& \text { and } \quad \psi_{i}=\frac{\left(U_{i}+U_{i-1}+\ldots+U_{i-w+1}\right)}{i} ; i \geq w .
\end{aligned}
$$

(1)

Here ' $w$ ' is called the span of the moving average. Choice of ' $w$ ' will be discussed later. If we are interested only in detecting a shift in $\theta$ in the positive direction, the control chart will have only the upper control limit. Let UCL be the upper control limit of the chart. UCL is chosen so as to have the desired in-control ARL. If the interest is in detecting a shift in negative direction, the control chart will have only the lower control limit (LCL). The control chart to detect shifts in both the directions, both LCL and UCL are required by the chart.

A nonparametric moving average chart gives an out-ofcontrol signal for the first sampling instant $i$, if

1. if $\Psi_{i} \geq \mathrm{UCL}$ (when interest is to detect upward permanent step shift)

2. if $\Psi i \leq \mathrm{LCL}$ (when interest is to detect downward permanent step shift)

3. if $\Psi i \leq \mathrm{LCL}$ or $\Psi i \geq \mathrm{UCL}$ (when interest is to detect permanent step shift in either direction)

In order to obtain LCL/UCL, we need to know the distribution of the charting statistics. Since the sequence of charting statistics, $\Psi_{i}, i=1,2, \ldots$ is a sequence of dependent variables, it may not easy to obtain an exact distribution of $\Psi_{i}, i=1,2, \ldots .$. In such cases, simulation technique can be used to obtain the control limits and ARL values. Further, since the distribution of $\Psi_{i}$ is discrete, many times, it will not be possible to get LCL/UCL that gives in-control ARL exactly equal to the desired value, say ARL(0). In that case, we choose that LCL/UCL for which in-control ARL is close to the desired ARL(0).

In the following section, we discuss Moving Average control charts based on two well-known nonparametric statistics namely sign and signed-rank statistic. 


\section{MOVING AVERAGE SIGN AND SIGNED-RANK CONTROL CHARTS}

Let $\mathrm{X}_{\mathrm{i}}=\left(\mathrm{x}_{i l}, \mathrm{x}_{i 2} \ldots, \mathrm{x}_{i n}\right)$ be a sample of size $\mathrm{n}$ drawn from a process having continuous distribution with process median $\theta$. Define

$U_{i}=\sum_{j=1}^{n} \operatorname{sign}\left(X_{i j}-\theta_{0}\right), \quad \mathrm{i}=1,2,3, \ldots$

Where,

$$
\operatorname{sign}\left(X_{i j}-\theta_{0}\right)=\left\{\begin{array}{cc}
1 & \text { if } X_{i j}>\theta_{0} \\
0 & \text { if } X_{i j}=\theta_{0} . \\
-1 & \text { if } X_{i j}<\theta_{0}
\end{array} .\right.
$$

A random variable $T_{i}=\frac{U_{i}+n}{2}$ binomial distribution with parameters $n$ and $p(\theta)$, where $p(\theta)=\operatorname{Pr}\left(X_{i j}>\theta_{0} \mid \theta\right)$. Suppose our interest is to detect a shift in the process median in a positive direction only. Using the definition of $\Psi i$, as given in equation (1), moving average sign control chart (MASCC) is defined, which declares the process to be out-of-control at instant $\mathrm{i}$, when $\Psi_{i} \geq U C L$ for the first time. The charting statistic $\Psi i$ of MASCC based on subgroup sample size $n$ and span of moving average $w$ is a discrete variable which assumes values between $-n$ and $n$ with a common difference $(2 / w)$. To implement the MASCC, one needs the values of the control limits that guarantee a specific in-control ARL and/or the false alarm rate for the chart.

Table 1 gives the in-control ARL values for various values of UCL and $w$ when the subgroup sample size is $n=10$. These values are simulated by using open source software $\mathrm{R}$ with 10,000 repetitions when the underlying process distribution is normal with parameters 0 and 1 . The values remain the same for any other underlying process distribution which is continuous with the in-control process median $\theta_{0}=0$. Since it is not possible to obtain UCL so as to have ARL(0) as desired, we choose UCL in such a way that the simulated ARL $(0)$ is close to the desired one. For example, if the desired ARL(0) is 1024, we can choose $\mathrm{UCL}=8$, when $\mathrm{w}=4$ and $\mathrm{n}=10$. We have entered the incontrol ARL values which are close to the desired incontrol ARL assuming that the desired in-control ARL is $\operatorname{ARL}(0)=1024$.

Table 1: Simulated values of ARL $(0)$ for MASCC, when $n=$ 10

\begin{tabular}{|c|c|c|c|c|c|}
\hline \multicolumn{2}{|c|}{$\mathrm{w}=2$} & \multicolumn{2}{c|}{$\mathrm{W}=3$} & $\mathrm{w}=4$ \\
\hline UCL & ARL(0) & UCL & ARL(0) & UCL & ARL $(0)$ \\
\hline 3 & 9.44 & 2.67 & 25.57 & 2.5 & 21.36 \\
\hline 4 & 19.47 & 3.33 & 26.99 & 3.0 & 35.31 \\
\hline 5 & 55.03 & 4.00 & 54.53 & 3.5 & 70.57 \\
\hline 6 & 179.91 & 4.67 & 426.03 & 4.0 & 148.84 \\
\hline 7 & 810.80 & 5.33 & 426.71 & 4.5 & 401.11 \\
\hline 8 & 4872.12 & 6.00 & 1506.41 & 5.0 & 1070.43 \\
\hline
\end{tabular}

A nonparametric control chart based on the signedrank statistic is described below.

Define

$U_{i}=\sum_{j=1}^{n} \operatorname{sign}\left(X_{i j}-\theta_{0}\right) R_{i j}^{+}, \quad i=1,2, \ldots$

Where,

$\operatorname{sign}\left(X_{i j}-\theta_{0}\right)=\left\{\begin{array}{cc}1 & \text { if } X_{i j}>\theta_{0} \\ 0 & \text { if } X_{i j}=\theta_{0} \\ -1 & \text { if } X_{i j}<\theta_{0}\end{array}\right.$

and $R_{t j}^{+}=1+\sum_{i=1}^{n} I\left(\left|x_{t i}-\theta_{0}\right|<\left|x_{t j}-\theta_{0}\right|\right)$ with $I(a<b)=1$ if $a$

$<b$ and 0 otherwise.

We can rewrite (2) as

$$
U_{i}=2 w_{i}^{+}-\frac{n(n+1)}{2}, \mathrm{i}=1,2,3, \ldots
$$

The charting statistic $\psi_{i}$ for Moving Average SignedRank Control Chart (MASRCC) is defined based on the $U_{i}$ as described in an equation (1).

We note that, $U_{i}=2 w_{i}^{+}-\frac{n(n+1)}{2}, \mathrm{i}=1,2,3, \ldots$,

Where, $w_{i}^{+}$is the well-known Wilcoxon Signed-rank Statistic (the sum of the ranks of the absolute values of the deviations corresponding to the positive deviations).

The charting statistic $\Psi i$ of MASRCC based on subgroup sample size $n$ and span of moving average $w$ is a discrete variable which assumes values between $(n(n+1) / 2)$ and $n(n+1) / 2$ with a common difference $(2 / w)$.

To implement the proposed MASRCC, one needs to know the values of the control limits that guarantee a specific incontrol ARL and/or the false alarm rate for the chart.

In Table 2 we gives the in-control ARL values ARL $(0)$ for positive-sided control chart for sample sizes $n=10$ and for $\mathrm{w}=2,3$ and 4 . These values are simulated in the same manner as in the case of MASCC.

Table 2: Simulated values of ARL(0) for MASRCC, when $n$ $=10$

\begin{tabular}{|c|l|c|c|c|c|}
\hline \multicolumn{2}{|l|}{$\mathrm{W}=2$} & \multicolumn{2}{c|}{$\mathrm{W}=3$} & \multicolumn{2}{c|}{$\mathrm{W}=4$} \\
\hline UCL & ARL(0) & UCL & ARL(0) & UCL & ARL $(0)$ \\
\hline 26 & 33.44 & 22.33 & 47.41 & 21.0 & 77.67 \\
\hline 27 & 39.75 & 23.00 & 54.07 & 21.5 & 90.58 \\
\hline 28 & 47.96 & 23.67 & 72.09 & 22.0 & 103.38 \\
\hline 29 & 55.81 & 24.33 & 72.71 & 22.5 & 112.04 \\
\hline 30 & 68.39 & 25.00 & 84.37 & 23.0 & 130.72 \\
\hline 31 & 82.35 & 25.67 & 114.28 & 23.5 & 150.14 \\
\hline 32 & 103.42 & 26.33 & 115.42 & 24.0 & 175.87 \\
\hline
\end{tabular}




\begin{tabular}{|l|l|l|l|l|l|}
\hline 33 & 124.85 & 27.00 & 134.78 & 24.5 & 199.51 \\
\hline 34 & 152.32 & 27.67 & 189.30 & 25.0 & 232.07 \\
\hline 35 & 194.43 & 28.33 & 189.89 & 25.5 & 273.38 \\
\hline 36 & 253.45 & 29.00 & 228.81 & 26.0 & 319.23 \\
\hline 37 & 313.12 & 29.67 & 325.02 & 26.5 & 370.52 \\
\hline 38 & 412.58 & 30.33 & 329.41 & 27.0 & 426.48 \\
\hline 39 & 542.53 & 31.00 & 403.16 & 27.5 & 513.37 \\
\hline 40 & 706.18 & 31.67 & 587.38 & 28.0 & 601.79 \\
\hline
\end{tabular}

\section{AVERAGE RUN LENGTH PERFORMANCE OF THE CONTROL CHARTS}

\section{PERFORMANCE OF MASCC:}

The nonparametric sign chart was proposed by Amin et al. [3]. The proposed moving average sign control chart will be compared with the sign chart and the Shewhart X-bar chart for various underlying process distributions. For comparison, the adjusted ARL values will be used. The adjusted ARL is computed by multiplying the actual ARL by the ratio (desired ARL(0) / actual ARL(0)).

Examination of Tables 3-5 leads to the following findings:

- The ARL values of the proposed moving average sign chart are smaller than those of the X-bar chart and the chart based on the sign statistic for all shifts, for every process distribution considered here and for every span (w) of moving average. It means that the proposed moving average sign chart outperforms for all shifts for all the process distributions considered here. Moreover, the performance of the moving average sign chart is significantly better than the X-bar chart for heavy-tailed distributions like the double exponential and Cauchy.

The performance of the moving average sign chart improves as the span of the moving average $(w)$ increase

- The performance of the moving average sign chart improves as the span of the moving average $(w)$ increase.

Table 3: ARL values for positive sided MASCC under Normal distribution when $\mathrm{n}=10$ and $\operatorname{ARL}(0)=1024$.

\begin{tabular}{|c|c|c|c|c|c|}
\hline \multirow{2}{*}{$\begin{array}{l}\text { Shift } \\
\square \square \square \\
\square_{\square} \square\end{array}$} & \multicolumn{3}{|c|}{ Moving average sign chart } & \multirow{2}{*}{$\begin{array}{c}\text { Sign } \\
\text { chart } \\
\text { UCL= } \\
10\end{array}$} & \multirow{2}{*}{$\begin{array}{r}\begin{array}{r}\text { X-bar } \\
\text { chart }\end{array} \\
\text { UCL= } \\
0.979\end{array}$} \\
\hline & $\begin{array}{c}\mathrm{W}=2, \\
\mathrm{UCL}=7\end{array}$ & $\begin{array}{c}\mathrm{w}=3, \\
\mathrm{UCL}=6\end{array}$ & $\begin{array}{c}\mathrm{w}=4, \\
\mathrm{UCL}=5\end{array}$ & & \\
\hline 0.0 & 1024.00 & 1024.0 & 1024.0 & 1024.00 & 1024.00 \\
\hline 0.2 & 137.54 & 79.50 & 67.61 & 235.10 & 145.91 \\
\hline 0.4 & 30.25 & 12.06 & 10.90 & 68.35 & 29.90 \\
\hline 0.6 & 10.11 & 3.53 & 3.55 & 24.66 & 8.69 \\
\hline 0.8 & 4.65 & 1.55 & 1.83 & 10.81 & 3.51 \\
\hline 1.0 & 2.78 & 1.00 & 1.27 & 5.62 & 1.90 \\
\hline 1.2 & 1.98 & 0.79 & 1.07 & 3.39 & 1.32 \\
\hline
\end{tabular}

Table 4: ARL values for positive sided MASCC under

Double Exponential distribution when $\mathrm{n}=10$ and

\begin{tabular}{|c|c|c|c|c|c|}
\multicolumn{7}{c|}{ ARL $(0)=1024}$. \\
\hline \begin{tabular}{c} 
Shift \\
\hdashline$\square$
\end{tabular} & \multicolumn{6}{|c|}{ Moving average sign chart } & $\begin{array}{c}\text { Sign } \\
\text { chart }\end{array}$ & $\begin{array}{c}\text { X-bar chart } \\
\text { UCL }=1.05\end{array}$ \\
\cline { 2 - 6 } & $\begin{array}{l}\text { W=2, } \\
\text { UCL=7 }\end{array}$ & $\begin{array}{l}\text { W=3, } \\
\text { UCL=6 }\end{array}$ & $\begin{array}{l}\text { W=4, } \\
\text { UCL=5 }\end{array}$ & UCL=10 & \\
\hline 0.0 & 1024.0 & 1024.00 & 1024.00 & 1024.00 & 1024.00 \\
\hline 0.2 & 54.59 & 25.38 & 21.53 & 113.20 & 206.62 \\
\hline 0.4 & 11.64 & 4.05 & 3.98 & 28.23 & 46.66 \\
\hline 0.6 & 4.77 & 1.64 & 1.90 & 11.11 & 13.32 \\
\hline 0.8 & 2.83 & 1.02 & 1.30 & 5.81 & 4.81 \\
\hline 1.0 & 2.07 & 0.82 & 1.09 & 3.65 & 2.30 \\
\hline 1.2 & 1.69 & 0.74 & 1.01 & 2.61 & 1.45 \\
\hline
\end{tabular}

Table 5: ARL values for positive sided MASCC under Cauchy distribution when $\mathrm{n}=10$ and $\operatorname{ARL}(0)=1024$.

\begin{tabular}{|c|c|c|c|c|c|}
\hline \multirow{2}{*}{$\begin{array}{c}\text { Shift } \\
\square \square \square \square \\
\square \square \square\end{array}$} & \multicolumn{3}{|c|}{ Moving average sign chart } & \multirow{2}{*}{$\begin{array}{c}\text { Sign chart } \\
\mathrm{UCL}= \\
10\end{array}$} & \multirow{2}{*}{$\begin{array}{c}\text { X-bar } \\
\text { chart } \\
\text { UCL= } \\
84.9\end{array}$} \\
\hline & $\begin{array}{c}\mathrm{w}=2, \\
\mathrm{UCL}=7\end{array}$ & $\begin{array}{c}\mathrm{w}=3, \\
\mathrm{UCL}=6\end{array}$ & $\begin{array}{c}\mathrm{W}=4, \\
\mathrm{UCL}=5\end{array}$ & & \\
\hline 0.0 & 1024.0 & 1024.0 & 1024.0 & 1024.00 & 1024.00 \\
\hline 0.2 & 13.06 & 4.62 & 4.55 & 31.41 & 1021.47 \\
\hline 0.4 & 3.52 & 1.20 & 1.48 & 7.62 & 1019.06 \\
\hline 0.6 & 2.22 & 0.84 & 1.13 & 4.04 & 1016.65 \\
\hline 0.8 & 1.80 & 0.76 & 1.03 & 2.87 & 1014.24 \\
\hline 1.0 & 1.59 & 0.71 & 1.01 & 2.33 & 1011.83 \\
\hline 1.2 & 1.51 & 0.70 & 0.99 & 2.02 & 1009.41 \\
\hline
\end{tabular}

\section{PERFORMANCE OF MASRCC:}

The nonparametric Signed-Rank control chart was proposed by Bakir [4] and was improved by introducing 2of-2 runs rule by Chakraborti and Eryilmaz [7]. The proposed chart MASRCC will be compared with the control chart by Chakraborti and Eryilmaz [7] along with the Shewhart X-bar chart in terms of the ARL values. Following tables, 13-18 give the ARL values for different shifts in the process median for $\mathrm{n}=10$ with desired $\operatorname{ARL}(0)=380$. Since the MASRCC is based on discrete charting statistic, it is not possible to get the exact desired ARL(0). We have obtained ARL values for different shifts using UCL that has ARL(0) close to the desired one. For comparison purpose, the ARL values are adjusted by multiplying the actual ARL value by the adjustment factor (desired ARL(0)/actual (ARL(0)).

Examination of Tables $6-8$ leads to the following findings:

- When the process underlying distribution is normal, the X-bar chart performs better than the 2-of-2 signedrank chart except for the small shifts ( shift $\leq 0.6)$ when the sample size $\mathrm{n}$ is large $(\mathrm{n}=10)$. 
- When the process underlying distribution is double exponential, the 2-of-2 signed-rank chart performs better only for small shifts ( shift $\leq 0.6$ ).

- When the process underlying distribution is Cauchy, the performance of the X-bar chart is uniformly worst as compared to the 2-of-2 signed-rank chart.

- The ARL values of the proposed moving average signed-rank chart are smaller than those of X-bar chart and the 2-of-2 signed-rank chart for all shifts, for every process underlying distribution and for every span (w) of moving average. It means that the proposed moving average signed-rank chart outperforms for all shifts under all the distributions. Moreover, the performance of the moving average signed-rank chart is significantly better than the X-bar chart for heavytailed process distributions like double exponential and Cauchy.

- The performance of the moving average signed-rank chart improves as the span of moving average (w) increases.

Table 6: ARL values for positive sided MASRCC charts under Normal distribution when $\mathrm{n}=10$.

\begin{tabular}{|c|c|c|c|c|c|}
\hline $\begin{array}{l}\text { Shift } \\
\square- \\
\square \square\end{array}$ & \multicolumn{2}{|c|}{$\begin{array}{l}\text { Moving Average Signed Rank } \\
\text { chart }\end{array}$} & $\begin{array}{l}\text { SR 2-of-2 } \\
\text { chart }\end{array}$ & $\begin{array}{c}\text { X-bar } \\
\text { chart }\end{array}$ \\
\cline { 2 - 6 } & $\begin{array}{c}\mathrm{W}=2, \\
\mathrm{UCL}=38\end{array}$ & $\begin{array}{c}\mathrm{W}=3, \\
\mathrm{UCL}=31\end{array}$ & $\begin{array}{c}\mathrm{W}=4, \\
\mathrm{UCL}=27\end{array}$ & $\mathrm{UCL}=33$ & $\mathrm{UCL}=0.88$ \\
\hline 0 & 380.00 & 380.00 & 380.00 & 380.00 & 380.00 \\
\hline 0.2 & 47.58 & 30.69 & 23.29 & 52.48 & 64.67 \\
\hline 0.4 & 10.06 & 6.01 & 4.32 & 13.10 & 15.73 \\
\hline 0.6 & 3.55 & 2.23 & 1.72 & 5.25 & 5.37 \\
\hline 0.8 & 1.86 & 1.33 & 1.12 & 3.12 & 2.51 \\
\hline 1.0 & 1.26 & 1.06 & 0.95 & 2.38 & 1.55 \\
\hline 1.2 & 1.05 & 0.97 & 0.90 & 2.11 & 1.18 \\
\hline
\end{tabular}

Table 7: ARL values for positive sided MASRCC charts under Double Exponential distribution when

$$
\mathrm{n}=10 \text {. }
$$

\begin{tabular}{|c|c|c|c|c|l|}
\hline \multirow{2}{*}{$\begin{array}{c}\text { Shift } \\
\square \square\end{array}$} & \multicolumn{3}{|c|}{$\begin{array}{c}\text { Moving Average Signed Rank } \\
\text { chart }\end{array}$} & $\begin{array}{c}\text { SR 2-of-2 } \\
\text { chart }\end{array}$ & $\begin{array}{l}\text { X-bar } \\
\text { chart }\end{array}$ \\
\cline { 2 - 6 } \\
$\begin{array}{c}\mathrm{W}=2, \\
\square\end{array}$ & $\begin{array}{c}\mathrm{W}=3, \\
\mathrm{UCL}=38\end{array}$ & $\begin{array}{c}\mathrm{W}=4, \\
\mathrm{UCL}=31\end{array}$ & $\mathrm{UCL}=27$ & $\mathrm{UCL}=33$ & $\mathrm{UCL}=0.93$ \\
\hline 0.00 & 380.00 & 380.00 & 380.00 & 380.00 & 380.00 \\
\hline 0.20 & 27.19 & 17.76 & 13.08 & 54.87 & 82.28 \\
\hline 0.40 & 5.89 & 3.69 & 2.72 & 10.50 & 21.43 \\
\hline 0.60 & 2.53 & 1.73 & 1.35 & 4.47 & 7.00 \\
\hline 0.80 & 1.58 & 1.19 & 1.04 & 2.94 & 2.98 \\
\hline 1.00 & 1.24 & 1.04 & 0.94 & 2.38 & 1.70 \\
\hline 1.20 & 1.08 & 0.97 & 0.91 & 2.16 & 1.23 \\
\hline
\end{tabular}

Table 8: ARL values for positive sided MASRCC charts under Cauchy distribution when $n=10$.

\begin{tabular}{|c|c|c|c|c|c|}
\hline \multirow{2}{*}{$\begin{array}{l}\text { Shift } \\
\square \square \\
\square \square\end{array}$} & \multicolumn{3}{|c|}{$\begin{array}{l}\text { Moving Average Signed Rank } \\
\text { chart }\end{array}$} & $\begin{array}{l}\text { SR 2-of-2 } \\
\text { chart }\end{array}$ & $\begin{array}{l}\text { X-bar } \\
\text { chart }\end{array}$ \\
\cline { 2 - 6 } & $\begin{array}{l}\mathrm{W}=2, \\
\mathrm{UCL}=38\end{array}$ & $\begin{array}{l}\mathrm{W}=3, \\
\mathrm{UCL}=31\end{array}$ & $\begin{array}{l}\mathrm{W}=4, \\
\mathrm{UCL}=27\end{array}$ & $\mathrm{UCL}=33$ & $\mathrm{UCL}=31.5$ \\
\hline 0.00 & 380.00 & 380.00 & 380.00 & 380.00 & 380.00 \\
\hline 0.20 & 8.58 & 5.39 & 4.00 & 11.43 & 377.48 \\
\hline 0.40 & 2.75 & 1.83 & 1.47 & 4.12 & 375.07 \\
\hline 0.60 & 1.86 & 1.29 & 1.11 & 2.91 & 372.65 \\
\hline 0.80 & 1.56 & 1.12 & 1.02 & 2.49 & 370.24 \\
\hline 1.00 & 1.41 & 1.06 & 0.96 & 2.32 & 367.83 \\
\hline 1.20 & 1.30 & 1.02 & 0.94 & 2.21 & 365.42 \\
\hline
\end{tabular}

\section{ROBUSTNESS OF THE MOVING AVERAGE CONTROL CHARTS AGAINST OUTLIERS:}

It is observed that there are situations in which the process is in-control, but a few outliers occasionally contaminate its output. A single extreme outlying observation may trigger an out-of-control signal while in fact; the process is in-control. It results in increasing the false alarm rate and decreasing the in-control ARL of the control chart. In this section, we are interested in studying the effects of distributional contamination on the proposed moving average control charts.

To study the robustness of proposed control charts against outliers, we consider underlying process data from contaminated normal distribution and contaminated double exponential distribution. It is a mixture of two normal distributions. The cumulative distribution function (c.d.f) of which is

$F(\mathrm{x}) \square(1 \square p) N(\square, 1) \square p N\left(\square, \sigma^{2}\right), \ldots$

where $0 \leq \mathrm{p} \leq 1$ and $\mathrm{N}\left(\square, \square^{2}\right)$, is the c.d.f. of a normal distribution with mean $\square$ and variance $\square^{2}>0$. We will refer $\mathrm{p}$ and $\square^{2}$ as the percentage of contamination and the extremity of contamination respectively. When $\square=0$, the process is in-control though producing occasional outliers. When $p=0$ and $\square=0$, equation (4) becomes c.d.f. of standard normal distribution. The in-control ARL values of the proposed nonparametric moving average control charts are computed using 10,000 simulations for each chart when subgroup sample size is $n=10$. The simulations are made for all possible combinations of $\left(\square^{2}, p\right)$ where $\square^{2}=4,9,16$ and $\mathrm{p}=0.01,0.05,0.10,0.20$.

From Table 9 to Table 13, it is observed that the in-control ARL values of the moving average sign chart and the moving average signed-rank chart are not affected by contamination of outliers for various combinations of the percentage of contamination and extremity of outliers.

The general conclusion of the robustness study against contamination by outliers is that the proposed nonparametric moving average charts are robust against contamination by outliers. 
Table 9: In-control ARL values of the X-bar chart for a stable process with occasional outliers for contaminated normal and double exponential distributions $(\mathrm{n}=10)$.

\begin{tabular}{|c|c|c|c|c|c|c|}
\hline \multirow{3}{*}{$\begin{array}{l}\text { Percentage of } \\
\text { contamination }\end{array}$} & \multicolumn{4}{|c|}{ Extremity of outliers } \\
\cline { 2 - 7 } & \multicolumn{2}{|c|}{$\begin{array}{c}\text { Normal Distribution } \\
\text { UCL }=0.883\end{array}$} & \multicolumn{2}{c|}{$\begin{array}{c}\text { Double Exponential } \\
\text { UCL }=0.93\end{array}$} \\
\cline { 2 - 7 } & $\sigma^{2}=4$ & $\sigma^{2}=9$ & $\sigma^{2}=16$ & $\sigma^{2}=4$ & $\sigma^{2}=9$ & $\sigma^{2}=16$ \\
\hline $\mathrm{p}=0 \%$ & 380.00 & 380.00 & 380.00 & 380.00 & 380.00 & 380.00 \\
\hline $\mathrm{p}=1 \%$ & 158.83 & 51.15 & 32.04 & 317.45 & 240.45 & 175.16 \\
\hline $\mathrm{p}=5 \%$ & 47.32 & 12.51 & 8.05 & 206.59 & 95.83 & 55.42 \\
\hline $\mathrm{p}=10 \%$ & 25.11 & 7.16 & 4.84 & 134.97 & 54.83 & 29.68 \\
\hline $\mathrm{p}=15 \%$ & 17.16 & 5.43 & 3.74 & 97.52 & 37.20 & 20.49 \\
\hline $\mathrm{p}=20 \%$ & 12.90 & 4.60 & 3.27 & 75.77 & 27.74 & 15.62 \\
\hline
\end{tabular}

Table 10: In-control ARL values of MASCC for a stable process with occasional outliers for contaminated normal distribution $(n=10)$.

\begin{tabular}{|c|c|c|c|c|l|l|l|l|l|}
\hline \multirow{2}{*}{$\begin{array}{l}\text { Percentage of } \\
\text { contamination }\end{array}$} & \multicolumn{9}{|c|}{ Extremity of Outliers } \\
\cline { 2 - 12 } & \multicolumn{3}{|c|}{$\sigma^{2}=4$} & \multicolumn{3}{c|}{$\sigma^{2}=9$} & \multicolumn{3}{c|}{$\sigma^{2}=16$} \\
\cline { 2 - 12 } & $\begin{array}{l}\mathrm{W}=2 \\
\mathrm{UCL}=7\end{array}$ & $\begin{array}{l}\mathrm{W}=3 \\
\mathrm{UCL}=6\end{array}$ & $\begin{array}{l}\mathrm{W}=4 \\
\mathrm{UCL}=5\end{array}$ & $\begin{array}{l}\mathrm{W}=2 \\
\mathrm{UCL}=7\end{array}$ & $\begin{array}{l}\mathrm{W}=3 \\
\mathrm{UCL}= \\
6\end{array}$ & $\begin{array}{l}\mathrm{W}=4 \\
\mathrm{UCL}= \\
5\end{array}$ & $\begin{array}{l}\mathrm{w}=2 \\
\mathrm{UCL}= \\
7\end{array}$ & $\begin{array}{l}\mathrm{w}=3 \\
\mathrm{UCL}= \\
6\end{array}$ & $\begin{array}{l}\mathrm{w}=4 \\
\mathrm{UCL}= \\
5\end{array}$ \\
\hline $\mathrm{p}=0 \%$ & 810.8 & 1486.9 & 1091.5 & 810.8 & 1486.9 & 1091.4 & 810.8 & 1486.9 & 1091.4 \\
\hline $\mathrm{p}=1 \%$ & 815.1 & 1484.8 & 1069.4 & 798.6 & 1480.4 & 1071.3 & 801.2 & 1469.5 & 1080.3 \\
\hline $\mathrm{p}=5 \%$ & 792.1 & 1496.9 & 1078.9 & 801.3 & 1491.3 & 1088.5 & 798.3 & 1497.3 & 1086.6 \\
\hline $\mathrm{p}=10 \%$ & 796.5 & 1490.8 & 1079.9 & 812.5 & 1477.6 & 1092.2 & 804.1 & 1478.1 & 1093.2 \\
\hline $\mathrm{p}=15 \%$ & 812.8 & 1463.3 & 1086.7 & 799.8 & 1479.1 & 1077.9 & 809.3 & 1487.3 & 1089.2 \\
\hline $\mathrm{p}=20 \%$ & 804.7 & 1496.4 & 1092.8 & 8.4 .2 & 1482.3 & 1090.4 & 800.6 & 1491.6 & 1079.9 \\
\hline
\end{tabular}

Table 11: In-control ARL values of MASCC for a stable process with occasional outliers for contaminated double exponential distribution $(\mathrm{n}=10)$.

\begin{tabular}{|c|c|c|c|c|c|c|c|c|c|}
\hline \multirow{3}{*}{$\begin{array}{l}\text { Percentage of } \\
\text { contamination }\end{array}$} & \multicolumn{9}{|c|}{ Extremity of Outliers } \\
\hline & \multicolumn{3}{|c|}{$\sigma^{2}=4$} & \multicolumn{3}{|c|}{$\sigma^{2}=9$} & \multicolumn{3}{|c|}{$\sigma^{2}=16$} \\
\hline & $\begin{array}{l}\mathrm{W}=2 \\
\mathrm{UCL}=7\end{array}$ & \begin{tabular}{|l}
$\mathrm{W}=3$ \\
$\mathrm{UCL}=6$
\end{tabular} & $\begin{array}{l}\mathrm{w}=4 \\
\mathrm{UCL}=5\end{array}$ & \begin{tabular}{|l|}
$\mathrm{W}=2$ \\
$\mathrm{UCL}=7$
\end{tabular} & $\begin{array}{l}\mathrm{W}=3 \\
\mathrm{UCL}=6\end{array}$ & $\begin{array}{l}\mathrm{W}=4 \\
\mathrm{UCL}=5\end{array}$ & $\begin{array}{l}\mathrm{W}=2 \\
\mathrm{UCL}=7\end{array}$ & $\begin{array}{l}\mathrm{W}=3 \\
\mathrm{UCL}=6\end{array}$ & $\begin{array}{l}\mathrm{W}=4 \\
\mathrm{UCL}=5\end{array}$ \\
\hline$p=0 \%$ & 822.4 & 1484.1 & 1077.6 & 822.4 & \begin{tabular}{|l|l}
1484.1 \\
\end{tabular} & 1077.6 & 822.4 & 1484.1 & 1077.6 \\
\hline $\mathrm{p}=1 \%$ & 799.6 & 1470.5 & 1088.1 & 803.2 & 1476.5 & 1076.3 & 811.2 & 1460.8 & 1063.2 \\
\hline$p=5 \%$ & 801.2 & 1491.3 & 1094.3 & 798.9 & 1489.3 & 1089.5 & 801.6 & 1486.2 & 1078.8 \\
\hline $\mathrm{p}=10 \%$ & 812.3 & 1474.9 & 1071.4 & 813.1 & 1473.6 & 1077.1 & 799.9 & 1479.4 & 1081.9 \\
\hline $\mathrm{p}=15 \%$ & 800.6 & 1488.2 & 1091.2 & 821.8 & 1493.2 & 1081.9 & 819.3 & 1469.9 & 1069.7 \\
\hline $\mathrm{p}=20 \%$ & 831.6 & 1490.0 & 1066.6 & 826.8 & 1488.4 & 1092.6 & 814.2 & 1488.7 & 1090.4 \\
\hline
\end{tabular}


Table 12: In-control ARL values of MASRCC for a stable process with occasional outliers for contaminated normal distribution $(\mathrm{n}=10)$.

\begin{tabular}{|c|c|c|c|c|c|c|c|c|c|}
\hline \multirow{3}{*}{$\begin{array}{l}\text { Percentage of } \\
\text { contamination }\end{array}$} & \multicolumn{9}{|c|}{ Extremity of Outliers } \\
\hline & \multicolumn{3}{|c|}{$\sigma^{2}=4$} & \multicolumn{3}{|c|}{$\sigma^{2}=9$} & \multicolumn{3}{|c|}{$\sigma^{2}=16$} \\
\hline & $\begin{array}{l}\mathrm{W}=2 \\
\mathrm{UCL}= \\
38\end{array}$ & $\begin{array}{l}\mathrm{w}=3 \\
\mathrm{UCL}= \\
31\end{array}$ & $\begin{array}{l}\mathrm{w}=4 \\
\mathrm{UCL}= \\
27\end{array}$ & $\begin{array}{l}\mathrm{W}=2 \\
\mathrm{UCL}= \\
38\end{array}$ & $\begin{array}{l}\mathrm{W}=3 \\
\mathrm{UCL}= \\
31\end{array}$ & \begin{tabular}{|l|}
$\mathrm{w}=4$ \\
$\mathrm{UCL}=$ \\
27
\end{tabular} & \begin{tabular}{|l|}
$\mathrm{w}=2$ \\
$\mathrm{UCL}=$ \\
38
\end{tabular} & $\begin{array}{l}\mathrm{w}=3 \\
\mathrm{UCL}= \\
31\end{array}$ & $\begin{array}{l}\mathrm{w}=4 \\
\mathrm{UCL}= \\
27\end{array}$ \\
\hline $\mathrm{p}=0 \%$ & 416.1 & 402.42 & 428.24 & 416.14 & 402.42 & 428.24 & 446.14 & 402.42 & 428.24 \\
\hline$p=1 \%$ & 412.4 & 399.41 & 425.84 & 416.91 & 398.23 & \begin{tabular}{|l}
422.21 \\
\end{tabular} & \begin{tabular}{|l|l}
409.13 \\
\end{tabular} & 395.63 & 421.14 \\
\hline $\mathrm{p}=5 \%$ & 421.8 & 396.18 & 432.40 & 410.44 & 406.25 & 429.51 & 414.51 & 398.57 & 430.56 \\
\hline $\mathrm{p}=10 \%$ & 409.9 & 395.16 & 430.01 & 410.29 & 401.65 & 427.36 & 421.35 & 401.62 & 427.31 \\
\hline $\mathrm{p}=15 \%$ & 416.8 & 400.15 & 434.27 & 420.42 & 397.74 & 431.12 & 418.14 & 403.24 & 431.96 \\
\hline $\mathrm{p}=20 \%$ & 421.2 & 395.17 & 425.85 & 413.61 & 403.32 & 426.53 & 411.39 & 394.96 & 417.99 \\
\hline
\end{tabular}

\section{CONCLUSIONS AND FUTURE SCOPE}

In this article, we proposed two nonparametric moving average control charts based on sign and signed-rank statistics. ARL of the proposed control charts is computed for normal, double exponential and Cauchy distributions. The proposed nonparametric moving average control chart based on the sign statistic perform superior than the nonparametric sign chart and the Shewhart X-bar chart for all distributions under the study. The performance of the another proposed nonparametric moving average control chart based on the signed-rank statistic is significantly superior than the Shewhart X-bar chart and the 2-of-2 control chart based on the signed-rank statistic for all considered distributions. . Comparison among the distributions shows that the under Cauchy distribution the proposed nonparametric moving average control charts based on the sign and signed-rank statistics perform significantly better than the normal and double exponential distributions for all shifts in the location. When span of the moving average $\mathrm{w}=4$, the proposed nonparametric moving average control charts perform superior for all distributions under study. In this article also studied the robustness study against contamination by outliers and proposed control charts are robust against contamination by outliers. We propose to extend the work for variability based on quantiles.

\section{REFERENCES}

[1] M. Abid, H. Z. Nazir, M. Riaz, Z. Lin, "Use of Ranked Set Sampling In Nonparametric Control Charts", Journal of the Chinese Institute of Engineers, vol.39, pp.627-636, 2016.

[2] R. W. Amin, A. J. Searcy, "A Nonparametric Exponentially Weighted Moving Average Control Scheme", Communications in Statistics- Simulation and Computation, Vol. 20, pp. 10491072, 1991.
[3] R. W. Amin, M. R. Jr. Reynolds, S. T. Bakir, "Nonparametric quality control charts based on the sign statistic", Communications in Statistic-Theory and Methods, vol. 24, pp. 1597-1623, 1995.

[4] S. T. Bakir, "A Distribution-Free Shewhart Quality Control Chart Based on Signed-Ranks", Quality Engineering, vol. 16, pp. 613-623, 2004.

[5] S. T. Bakir, "Distribution-Free Quality Control Charts Based On Signed- Rank-Like Statistics", Communications in Statistics- Theory and Methods, Vol. 35, pp. 743-757, 2006.

[6] S.T. Bakir, MR Jr. Reynolds, "A Non-Parametric Procedure for Process Control Based on Within-Group Ranking", Technometrics, Vol. 21, pp. 175-183, 1979.

[7] S. Chakraborti, S. Eryilmaz, "A nonparametric Shewhart-type signed-rank control chart based on runs", Communications in Statistics-Simulation and C0mputations, vol. 36, pp. 335-356, 2007.

[8] S. Chakraborti, P. Van der Laan, S. T. Bakir, "Nonparametric Control Charts: An Overview and Some Results", Journal of Quality Technology, Vol. 33, pp. 304-315, 2001.

[9] M. L.I. Coelho, M. A. Graham, S. Chakraborti, "Nonparametric Signed-Rank Control Charts With Variable Sampling Intervals", Quality and Reliability Engineering International, Vol. 33, Issue 8, pp. 2181-2192, 2017.

[10] V. B. Ghute, D. T. Shirke, "Nonparametric Signed-Rank Control Chart for Bivariate Process Control", Quality Technology and Quantitative Management, Vol. 9, Issue 4, 317-328, 2012.

[11] V Jayathavaj, A. Pongpullponsak, "A Simulation Study on The Performance of the Sign Test, Mann-Whitney Test, HodgesLehmann Estimator and Control Charts for Normal and Weibull Data" International Journal of Industrial Engineering Computations, Vol. 5, Issue 4, pp. 561-574, 2014.

[12] S. K. Khilare , D. T. Shirke, "A Nonparametric Synthetic Control Chart Using Sign Statistic", Communications in Statistics-Theory and Methods, vol. 39, pp. 3282-3293, 2010.

[13] S. K. Khilare, D. T. Shirke, "Nonparametric Synthetic Control Charts for Process Variation", Quality and Reliability Engineering International, vol. 28, pp. 193-202, 2012.

[14] S. K. Khilare, D. T. Shirke, "Steady-State Behavior of Nonparametric Control Charts Using Sign Statistic", Production, vol. 25, pp. 739-749, 2015.[15] M. B. C. Khoo, P. W. Yap, "Joint Monitoring of Process Mean and Variability With a Single Moving Average Control Chart", Quality Engineering, Vol. 17, pp. 51-65, 2005. 
[16] V. Y. Pawar, D. T. Shirke, "A Nonparametric Shewhart-Type Synthetic Control Chart", Communications in StatisticsSimulation and Computation, vol. 39, pp.1493-1505, 2010.

[17] V. Y. Pawar, D. T. Shirke, "Nonparametric Moving Average Control Chart for Process Variability", International Journal of Engineering Research and Technology, Vol. 3, Issue 6, 15701578, 2014.

[18] V. Y. Pawar, D. T. Shirke, S. K. Khilare "Steady-State Behavior of Nonparametric Synthetic Control Chart Using Signed-Rank Statistic", Pakistan Journal of Statistics and Operations Research, Vol. 14, Issue1, pp. 185-198, 2018.

[19] V. Y. Pawar, D. T. Shirke, S. K. Khilare "A Nonparametric Control Chart for Process Variability Based on Quantiles", International Journal of Statistics and Economics, Vol. 19, No. 3, pp. 56-64, 2018

[20] D. T. Shirke, M. S. Barale, "A Nonparametric CUSUM Chart for Process Dispersion", Quality and Reliability Engineering International, Vol. 34, No. 5, pp. 858-866, 2018.

\section{Authors Profile}

Vilas Y. Pawar is an Associate Professor of Statistics in the PDVP College, Tasgaon, India. He received his Ph. D. in Industrial Statistics 2015 (Nonparametric control charts) from the Shivaji University Kolhapur, India. His main research area of interest is Statistical Control Charts (parametric and nonparametric). His research published in journals Communications in Statistics-Simulation and computation and International Journal of Engineering Research and Technology.

Digambar T. Shirke is Professor of Statistics, Department of statistics, Shivaji University Kolhapur, India. He received his Ph. D. in inference 1993 (A Study of the Confidence Regions of the Parameters) from the Shivaji University, Kolhapur, India. His current research interests include the Statistical modelling and related inference, Statistical Control Charts (Parametric, Nonparametric, Data-Depth based), Data Mining and computational statistics. He has published more than 40 papers in various peer-reviewed journals.

Shashikant K. Khilare is a Assistant Professor of the Statistics, Department of statistics, R. B. Narayanrao Borawake College, Shrirampur, India. He received his $\mathrm{Ph}$. D. in Industrial Statistics 2012 (Fraction Nonconforming Control Charts) from the Shivaji University, Kolhapur, India. His research interest area is statistical Control Charts (parametric and nonparametric). $\mathrm{He}$ has published nine papers in peer-reviewed journals. 